\title{
The relationship between asthma admission rates, routes of admission, and socioeconomic deprivation
}

\author{
J.P. Watson*, P. Cowen**, R.A. Lewis*
}

The relationship between asthma admission rates, routes of admission, and socioeconomic deprivation. J.P. Watson, P. Cowen, R.A. Lewis. (C)ERS Journals Ltd 1996.

ABSTRACT: This study aimed to explore the relationship between hospital admissions for asthma and socioeconomic deprivation.

A retrospective study examined one year of hospital admissions for asthma in the West Midlands region of England $(n=10,044)$, and in one of the region's wealthier districts, Worcester $(n=251)$. Age standardized admission ratios (SARs) for asthma, and the routes of hospital admission, were compared with the Townsend Deprivation Index for the place of residence.

Asthma SAR was strongly associated with deprivation as measured by the Townsend Index for the district of residence (Spearman rank correlation coefficient $\rho=0.65$; $\mathrm{p}=0.004)$. Asthma admission rates for all age groups, except those aged over 65 yrs, were higher in poorer districts. A significantly greater proportion of emergency admissions in poorer districts came via Accident and Emergency departments, rather than general practitioner referrals $(\rho=0.76 ; p<0.001)$. Within Worcester District, SAR was associated with Townsend Index for the ward of residence $(\rho=0.39$; $\mathbf{p}<0.001)$. This remained significant after excluding repeat admissions $(\rho=0.45$; p $<0.001$ ).

We conclude that asthma admissions are strongly associated with deprivation in the community. Differences in the health care received during acute exacerbations by asthma patients from different economic backgrounds is likely to be an important factor in this relationship.

Eur Respir J., 1996, 9, 2087-2093.
Asthma causes considerable morbidity. Approximately $6 \%$ of the British population suffer from asthma and the prevalence is increasing [1-4]. Approximately 2,000 deaths from asthma occur in the UK each year. The association between poor socioeconomic circumstances and many aspects of ill health has been well-established, and the effect of this on total (all cause) hospital admission rates in the West Midlands has been highlighted by the West Midlands Regional Director of Public Health [5].

Asthma has been thought to be an exception to the general trend of increased disease in the poor, being regarded as a disease of higher social classes, and a number of studies have supported this view [6-9]. Other reports have shown no association between the prevalence of asthma and socioeconomic status [10-14]. Published reports of asthma mortality rates in Britain have also given conflicting results. Asthma is one of the few diseases with no association between mortality rate and socioeconomic indicators for the Area Health Authority of residence [15]. However, a more recent study has shown an increased mortality rate for asthma in males in the social classes defined by manual occupations [16].

We know of no previous studies of the relationship between socioeconomic circumstances and hospital admissions for asthma in Britain. We therefore examined the relationship between hospital admission rates for asthma and deprivation in the community.
*Dept of Respiratory Medicine, Worcester Royal Infirmary, Worcestershire, UK. **West Midlands Regional Respiratory Audit Office, Good Hope Hospital, Sutton Coldfield, West Midlands, UK.

Correspondence: J.P. Watson Killingbeck Hospital

York Road

Leeds LS14 6UQ

UK

\section{Keywords: Asthma}

emergency service in hospital

patient admission

socioeconomic factors

Received: December 291995

Accepted after revision June 281996

\section{Setting}

The area of study was the West Midlands Regional Health Authority. This has a population of just over 5 million, and includes the large industrial conurbation of Birmingham, affluent suburban areas, and rural farming communities. For health service administrative purposes, it was made up of 18 Health Districts (population $161,500-490,000$ ) during the period covered by this study. There are large ethnic minority populations in some districts, with up to $13.3 \%$ Afro-Caribbean and $24 \%$ South Asian. A breakdown of admissions by ethnic groups was not available. We looked in more detail at Worcester District, one of the wealthier parts of the region, with a population of 243,700 , of whom about one third live in the market city of Worcester and the rest in smaller towns and rural villages. Over $99 \%$ of the population are Caucasian.

\section{Deprivation Index}

The Townsend Index [17] was chosen as the measure of deprivation. This has been shown to be the best currently available measure of social deprivation in this 
country for predicting workload in general practice [8]. The index was derived from the 1991 census data obtained from the Office of Population Censuses and Surveys (OPCS). It is based on the percentage of economically active adults who are unemployed, the percentage of households with no cars (a surrogate for current income), the percentage of owner occupied homes (a longer term indicator of income), and the percentage of households with more than one person to a room. It is calculated to give a regional mean of zero, with greater deprivation resulting in a higher index value and wealthier areas having a negative value. The values for districts in the West Midlands region range from -3.99 to +7.45 . Worcester District has an index of -3.88 .

\section{Regional study of admission rates}

Finished consultant episodes (FCE) for asthma were obtained from the West Midlands Health Information System, recorded by age, sex, route of admission, and district of residence for the year April 1991 until March 92. In most cases, one FCE corresponds to one admission; however, if the patient is transferred to the care of another consultant during the hospital stay, this will count as a second FCE. We have assumed that the proportion of admissions in which such transfers of care occur does not vary significantly between districts. The population for each district was obtained from the 1991 census. Admission rates were calculated as FCE per 1,000 population.

One hospital did not distinguish between Accident and Emergency department (A\&E) admissions and general practitioner (GP) referrals in the coding of their patients; therefore, the district which it serves was excluded from the analysis of routes of admission but was included in the rest of the study. There is no evidence that a significant number of residents from outside this district were admitted to that hospital.

Because the asthma admission rates were higher in children, and the age distribution of the districts was not uniform, with higher proportions of children in the poorer districts, we calculated an age standardized admission ratio (SAR). This was calculated as the observed number of admissions for each district divided by the number that would have been expected had the age specific rates for the whole region applied.

Total asthma admission rates (but not SARs) were also calculated for each district for the years April 1989 until March 1990 and April 1990 until March 1991. Districts were classified as predominantly rural $(n=8)$ or predominantly urban $(n=10)$, according to the criteria of the West Midlands Regional Director of Public Health [19].

\section{District study}

All patients resident in Worcester District Health Authority (population 243,700) who were admitted to hospital in the year April 1993 until March 1994 with a primary diagnosis of asthma were included in the study. This more recent year was chosen because more detailed information was available from the District Health
Authority. Hospital admission dates were used to exclude multiple FCEs due to transfer between consultants, to produce a list of actual hospital admissions. The electoral ward of residence was determined from the post code. There are 65 wards in Worcester District (mean population 3,532, range 1,070-8,916).

Because the number of patients admitted from many of the individual wards was small, wards were listed in rank order of Townsend Index and aggregated into 10 "ward groups" with similar populations (mean 24,370, range 22,056-26,896). Each "ward group", therefore, represents an approximate population decile for deprivation (e.g. Group 1 combines the four poorest wards, combined population 24,307; Group 10 combines the nine wealthiest wards, combined population 24,133 ). The cut-off points between the groups were selected to give group populations as close as possible to the mean, but exactly equal populations could not be achieved because of variations in the populations of wards. The Townsend Index was recalculated for each "ward group".

Admission rates and SARs (standardized for the district) were calculated for each ward and for each "ward group" in the same way as for districts in the regional study. The results were calculated for: 1) all admissions within the year; and 2) after excluding repeat admissions within the year, so each individual patient was counted only once.

\section{Statistical analysis}

Pearson's product moments were used to calculate regression lines, but because the distribution of the Townsend Index was skewed, Spearman's rank correlation coefficients $(\rho)$ were used to assess statistical significance of associations between Townsend Index and admission rates. All calculations were performed using the software package C-Stat version 1.1 (Oxtech 1991).

\section{Results}

\section{Admission rates}

The total population of the West Midlands in 1991 was 5,230,067. The total number of FCEs for asthma in 1991-1992 was 10,044, giving a total admission rate of 1.91 per 1,000 for the region (range for districts 1.02-3.02). The rates were higher for children, declining with age. In children, rates were higher for boys than girls, but adult females had higher rates than males (table 1). There was a slight upward trend in asthma admission rates from the previous years (19891990: 1.57; 1990-1991: 1.70 FCE per 1,000).

Table 1. - Admission rates (FCE per 1,000 population) by age and sex for West Midlands Region, 1991-1992

\begin{tabular}{lrrrrrr}
\hline Age yrs & $0-4$ & $5-14$ & $15-44$ & $45-64$ & $>65$ & Total \\
\hline Male & 12.0 & 3.6 & 0.73 & 0.90 & 1.09 & 2.01 \\
Female & 5.8 & 2.3 & 1.52 & 1.32 & 1.31 & 1.82 \\
Total & 9.0 & 3.0 & 1.12 & 1.11 & 1.22 & 1.91 \\
\hline
\end{tabular}

FCE: finished consultant episodes. 


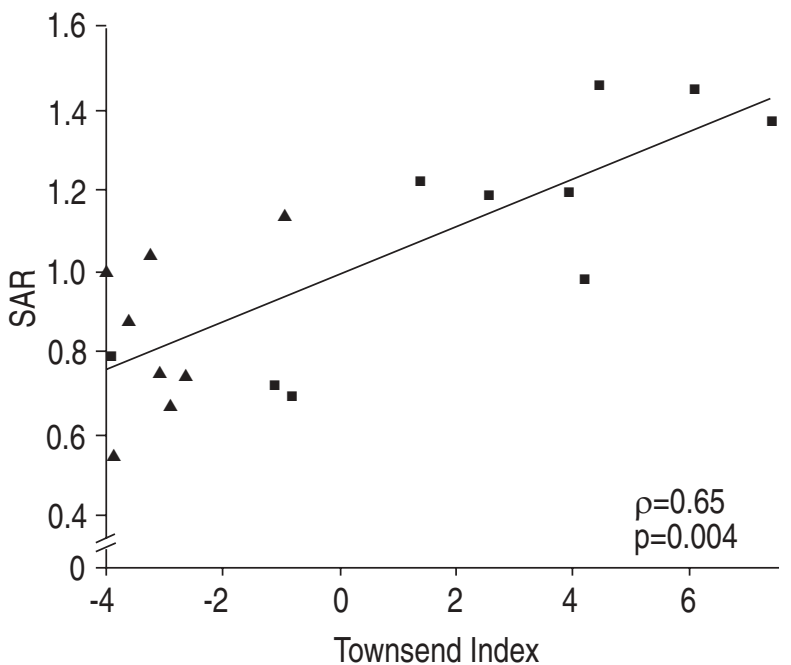

Fig. 1. - Relationship between Townsend Index and standardized admission ratio (SAR) for districts in the West Midlands region, 1991-1992. - : urban districts; $\boldsymbol{\Delta}$ : rural districts. Regression line and statistics are for all districts combined.

\section{Townsend Index and regional admissions}

There was a strong association between the SAR for asthma and the Townsend Index for each district $(\rho=0.65$; $\mathrm{p}=0.004$ ) (fig. 1). Worcester District had the lowest SAR of 0.55 .

When the different age groups were studied separately, the association between Townsend Index and admission rate was consistent for all age groups except for those aged over 65 yrs. There was a 2.5-5 fold difference between the highest and lowest district admission rate for each age group (table 2).

There was an association between total admission rate and Townsend Index in each of the three years (1989$1990: \rho=0.61, p<0.01 ; 1990-1991: \rho=0.58, p<0.02 ; 1991-$ 1992: $\rho=0.68, p=0.002$ ).

The Townsend Index is calculated to give a regional mean of zero. The mean (SD) Townsend Index was 2.43 (3.54) for predominantly urban districts, and -3.04 (0.97) for predominantly rural districts. When examined separately, the association between SAR and Townsend Index remained significant for the urban districts $(\rho=0.79$; $\mathrm{p}=0.006$ ) but was not significant for the rural districts.

\section{Routes of admission}

Of the total 9,560 admissions in the 17 districts included in the study of routes of admission, 9,258 (97\%) were emergencies. Of these, 3,358 (36\%) were via A\&E, $5,334(58 \%)$ were referred by general practitioners, and $566(6 \%)$ were by other routes, such as direct admissions from out-patient clinics.

The proportions of acute asthma patients admitted via A\&E in individual districts ranged $10-62 \%$. There was a significant association between Townsend Index (for district of residence) and the proportion of emergency asthma admissions via $\mathrm{A} \& \mathrm{E}(\rho=0.76 ; \mathrm{p}<0.001)$ (fig. 2$)$.

There was an association between the rate of $A \& E$ asthma admissions per 1,000 population and Townsend Index $(\rho=0.83 ; p<0.001)$ (fig. 3a). There was no association between the rates of GP referrals for emergency asthma admission and Townsend Index $(\rho=0.33 ; p>0.1)$ (fig. 3b). There was also no association between Townsend Index and elective asthma admissions or admissions from out-patient clinics.

\section{Worcester District}

There were 251 admissions of 201 individual patients in the year studied, giving a total admission rate of 1.03 per 1,000 , and, excluding readmissions, a rate of 0.82 per 1,000 . The total asthma admission rate was similar to the rate of 1.02 per 1,000 for Worcester District in 1991-1992 used in the regional study. Of these admissions, 226 (90\%) were to one hospital. Fifteen admissions were to other hospitals within the West

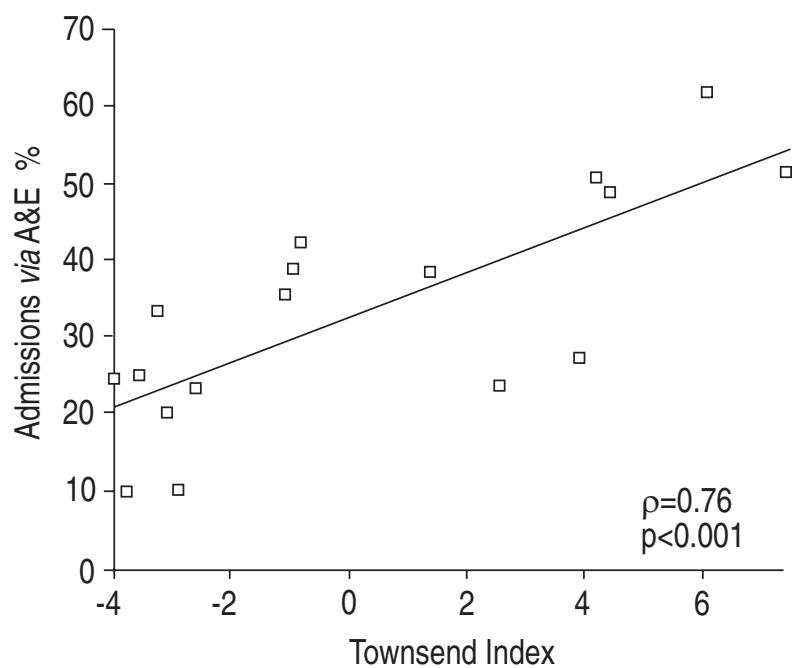

Fig. 2. - Relationship between proportion of acute asthma admissions via Accident and Emergency (A\&E) department and Townsend Index for district of residence, for districts in the West Midlands region, 1991-1992.

Table 2. - Admission rates (FCE per 1,000 population) for each age group, and relationship with Townsend Index for districts in the West Midlands Region, 1991-1992

\begin{tabular}{lcccccc}
\hline Age group yrs & $0-4$ & $5-14$ & $15-44$ & $45-64$ & $>65$ & Total \\
\hline $\begin{array}{l}\text { Regional asthma } \\
\text { admission rate }\end{array}$ & 9.0 & 3.0 & 1.12 & 1.11 & 1.22 & 1.91 \\
$\begin{array}{l}\text { District rates range } \\
\begin{array}{l}\text { for relationship with } \\
\text { Townsend Index }\end{array}\end{array}$ & $5.74-14.21$ & $1.38-4.80$ & $0.58-1.68$ & $0.41-2.10$ & $0.66-2.03$ & $1.02-3.02$ \\
p-value & 0.60 & 0.51 & 0.65 & 0.65 & 0.44 & 0.68 \\
\end{tabular}

FCE: finished consultant episodes. 
a)

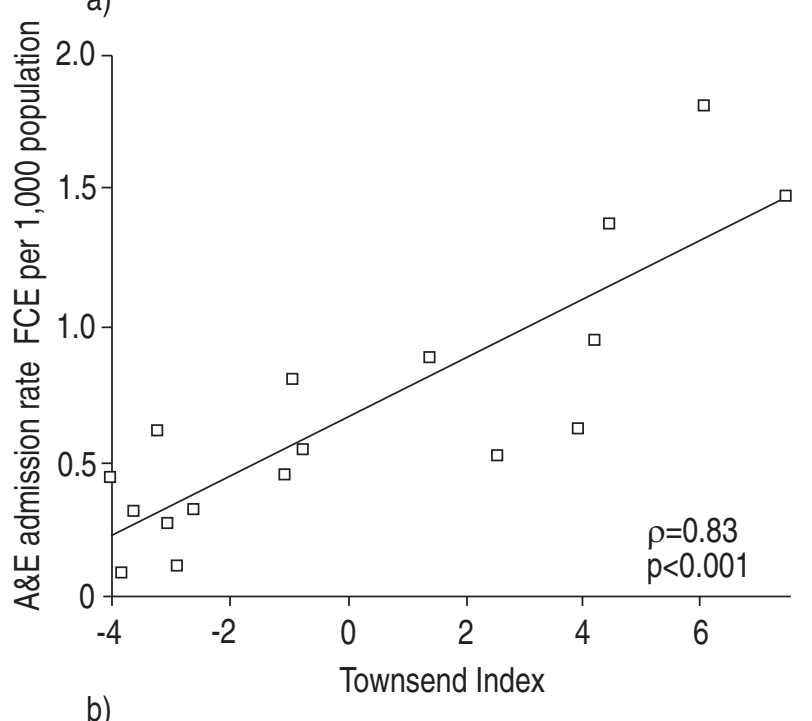

b)

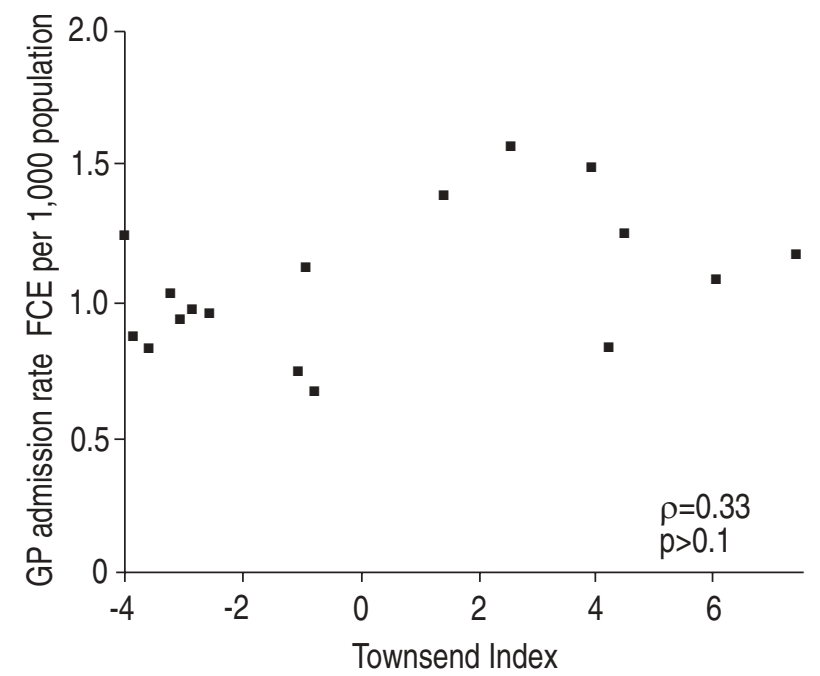

Fig. 3. - Relationship between Townsend Index and admission rates (FCE per 1,000 population) by different routes: a) Accident and Emergency (A\&E) admissions; and b) general practitioner (GP) referrals, for districts in the West Midlands region, 1991-1992. FCE: finished consultant episode.

Midlands region, and $10(4 \%)$ to hospitals in a neighbouring region.

When individual wards were analysed, there was an association between the Townsend Index and SAR for all admissions $(\rho=0.39 ; p<0.001)$, and after excluding repeat admissions $(\rho=0.45 ; p<0.001)$ (fig. 4). These associations remained significant for males and females, and for children (aged under 15 yrs) and adults, when analysed separately. More detailed analysis of narrower age bands was not carried out because of the relatively small numbers of patients in each age group. When the "wards groups" were analysed, the association between SAR and Townsend Index was more consistent. Townsend Index was associated with SAR for all admissions $(\rho=0.78 ; p=0.008)$ and after excluding repeat admissions $(\rho=0.94 ; \mathrm{p}<0.001)$ (fig. 5$)$.

The total number of admissions via A\&E was 62 (25\%). This was higher than the number for 1991-1992 (24; $10 \%$ ). There was no relationship between the proportion of admissions via A\&E and the Townsend Index

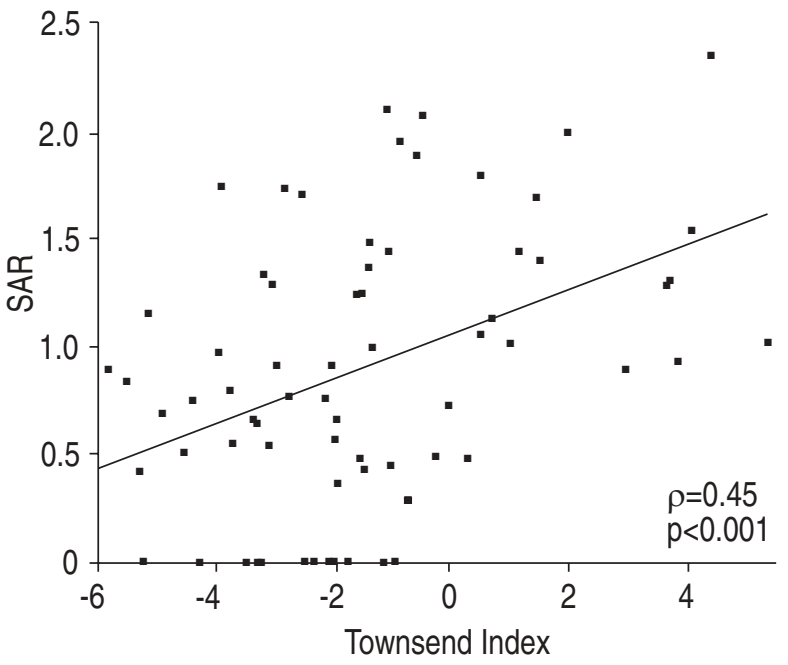

Fig. 4. - Relationship between Townsend Index and standardized admission ratio (SAR) for electoral wards in Worcester District, excluding readmissions, 1993-1994.

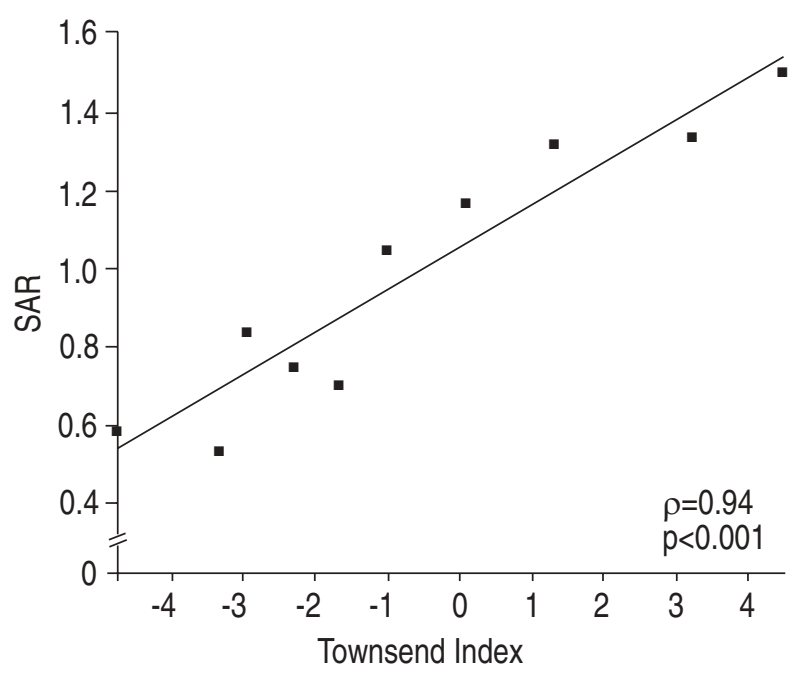

Fig. 5. - Relationship between Townsend Index and standardized admission ratio (SAR) for "ward groups" in Worcester District, excluding readmissions, 1993-1994.

of the electoral ward or "ward group" of residence. When GP referrals alone were analysed (excluding A\&E admissions), the relationship between SAR and Townsend Index remained significant both for individual wards $(p=0.40 ; p<0.001)$ and "ward groups" $(\rho=0.84, p=0.002)$.

\section{Discussion}

This study has shown a clear association in the West Midlands Region between age SARs for asthma and deprivation as indicated by Townsend Index. A similar association was found within an individual relatively wealthy district with a low overall asthma admission rate. The relationship applies for both sexes and for all age groups (except those aged over $65 \mathrm{yrs}$, in whom there is likely to be more diagnostic uncertainty). The Worcester District study also demonstrates that the relationship is not just due to multiple readmissions of the same patients, but that there are more individuals admitted with asthma from the poorer communities. 
Higher hospital admission rates for asthma in poorer communities have been reported in the USA [20], but since the accessibility and cost of appropriate out-patient health care are dependent on personal financial circumstances this is likely to influence morbidity and hospitalization [21]. In Britain, access to primary medical care and to hospital admission is free of charge to all patients, and so differences in the ability of patients to pay cannot account for our findings.

Over $90 \%$ of patients in Worcester District were admitted to one hospital, making it unlikely that the higher admission rates in more deprived areas can be accounted for by differences between hospitals in the criteria for admission for asthma or the availability of hospital beds.

Whilst it is probable that there may be some inaccuracies in the data for admissions related to errors of diagnosis, coding and recording, it is unlikely that there would be a systematic bias in such errors both in paediatric and adult medicine departments across the region. It is even less likely that such a bias could occur within a single hospital.

It is unlikely that the findings have been significantly distorted by underestimating admission rates in rural districts due to admissions to hospitals in neighbouring regions, which accounted for only $4 \%$ of the admissions from Worcester District. Furthermore, the relationship between deprivation and admission rates remained significant for the urban districts, which are at the centre of the region.

The calculated admission rates will be influenced by errors in the 1991 census data [22]. There was an estimated underenumeration of $2.2 \%$, which was not random, with greater numbers missing among young males in inner city areas [23]. An underestimation of the population would lead to an overestimation of the admission rate. However, the relationship between admission rate and Townsend Index was seen in all age groups and both sexes.

The greater populations of Asians in the more deprived districts of the region may contribute to the higher admission rates. Increased asthma admission rates in Asians have been reported in Birmingham [24] and elsewhere in Britain [25-27]. However, Asians make up only $0.5 \%$ of the population in Worcester District, so that ethnic differences in asthma admission rates cannot account for the relationship between asthma admissions and Townsend Index within this district.

We therefore believe the association between admission rates and material deprivation to be genuine. Hospital admission rates depend on the prevalence of the disease, the severity of the disease in those who have it, and their medical care. Community surveys in Britain have not shown any increased prevalence of asthma in people of poorer socioeconomic status [6-14]. The increased hospital admission rate may, therefore, be due to increased severity of asthma, differences in the medical care received by asthma patients, or a combination of these factors.

Our study shows a clear relationship between deprivation in the district of residence and the proportion of asthma admissions presenting via A\&E rather than being referred by GPs. This is consistent with a previous report from a two centre study [28] that the proportion of asthma admissions who were self-referred to casualty was $68 \%$ in a more deprived district compared with $30 \%$ in a wealthier district. The admission rates for GP referrals in the West Midlands were not related to deprivation in the districts; therefore, the additional admissions in poorer districts appear to be related to increased self-referrals via A\&E.

This suggests that variations in the way asthma patients use health services is an important factor in the increased admission rates in poorer districts. Although it is possible that GPs in more deprived districts might refer relatively fewer of the patients that present to them with acute severe asthma, there is no evidence to support this. It is more likely that in poorer districts a higher proportion of patients suffering from severe asthma exacerbations present to $A \& E$, rather than to their GP. The National Asthma Attack Audit [29] showed that patients attending A\&E are much more likely to be admitted to hospital than those presenting to their GP with a similar severity of asthma. This is consistent with the finding that the increase in asthma admission rates for children in Croydon (South London) between 1978 and 1991 was accompanied by a dramatic rise in A\&E attendances, while there was only a small increase in GP consultations for asthma [30].

There may be several real or perceived differences between wealthier and poor districts which influence whether patients with asthma choose to attend A\&E rather than consult their GP, including previous advice to do so, a belief that they will receive attention more quickly, lack of confidence in the GP, or the availability of nebulized bronchodilators [31, 32]. Patients in the wealthier, more rural districts in the West Midlands may live further away from a hospital. However, the fact that the relationship between admission rates and deprivation holds for urban districts alone, where there is less variability in the distance to hospital, suggests that this is not the major factor. A study of children admitted to hospital in the northern English town of Wakefield for acute nontrauma conditions (of which asthma was the most common) found no correlation between the proportion admitted via A\&E and the distance of the home from the hospital [33].

Differences in the use of A\&E departments may reflect other differences in the health care received by asthma patients. Over half of the adults attending a London Hospital A\&E for asthma had chronic persistent symptoms prior to presentation, and nearly all of these were on inadequate treatment [34]. The fact that asthma is often underdiagnosed and undertreated has been repeatedly demonstrated [12, 29, 35-37]. If the treatment obtained by asthmatics in more deprived districts is less adequate, this might contribute to increased morbidity and, hence, increased hospitalization. Previous studies have reported less adequate treatment of asthma in children [38, 39] and adults [40] in lower socioeconomic classes, although a more recent survey of children [14] showed no evidence of such a trend.

Increased use of A\&E departments is not the only reason for higher asthma admission rates in poorer communities, since in Worcester District the admission rates by GP referral were higher in more deprived wards. Asthma admission rates among adult males in Britain have been shown to be related to community 
morbidity [41]. It is possible that there may be an increased morbidity in poorer communities. A number of studies have found an increased frequency and severity of symptoms in asthmatic children [13, 14] and adults [40] of lower socioeconomic status. The Third National Morbidity Study in General Practice showed a trend of increasing asthma consultation rates for females (but not males) from social class I+II to IV+V [42]. A higher prevalence of disability due to asthma among females in lower social classes has been reported [43]. An increased morbidity among asthmatics from poorer backgrounds would be consistent with the finding of higher asthma mortality rates among males in the social class groups of manual occupations [16].

If asthmatics in poorer communities do suffer an increased morbidity, our results suggest that differences in the health care they receive may play a significant role. However, although we are aware of the ecological fallacy of assuming that higher admission rates in more deprived communities necessarily indicates that there is a higher admission rate for poorer individual patients, there are a number of environmental factors which may also contribute to an association between asthma morbidity and poverty. Asthma may be exacerbated by damp [44, 45] or mouldy [46] housing conditions, although the evidence is not conclusive [47]. Smoking and passive exposure to cigarette smoke in the home is more common among people in lower income groups [13, 48], and may increase the morbidity among asthmatics [49]. Although parental smoking has not been shown to increase the risk of hospital admissions for acute asthma in children $[50,51]$, it is possible that smoking may contribute to the relationship found in this study. There may be greater levels of atmospheric pollution in the more urban areas, which tend to be more deprived. In Birmingham, the major city in the West Midlands region, a temporal association has been found between pollution levels and asthma exacerbations [52] and admissions [53], and asthma admissions among preschool children are higher in those living close to major roads [54]. However, there was no relationship between hospital admission rates for asthma and recorded ambient levels of nitrogen dioxide, black smoke, or sulphur dioxide in the ward of residence, after correcting for socioeconomic differences [55].

In conclusion, we have found a strong relationship between admission rates for asthma and socioeconomic deprivation in the community, both at a regional level and within one of the wealthier districts in the region. The greater number of asthma admissions through Accident and Emergency Departments in more deprived districts is a major factor contributing to this relationship. Inequalities in the provision or uptake of health care for asthma need to be addressed. The other possible causes for the poverty-related difference in admission rates need further evaluation.

\section{References}

1. Fleming DM, Crombie DL. Prevalence of asthma and hay fever in England and Wales. BMJ 1987; 294: 279-283.

2. Fleming DM, Cross KW, Garcia Olmos L, Crombie DL. Changes in practice morbidity between the 1970 and
1981 national morbidity surveys. Br J Gen Pract 1991; 41: 202-206.

3. Ayres JG, Noah ND, Fleming DH. Incidence of episodes of acute asthma and acute bronchitis in general practice, 1976-1987. Br J Gen Pract 1993; 43: 361364.

4. Anderson HR, Butland BK, Strachan DP. Trends in prevalence and severity of childhood asthma. BMJ 1994; 308: 1600-1604.

5. West Midlands Regional Health Authority. Action for Health. Report of the Regional Director of Public Health. Birmingham, West Midlands Regional Health Authority, 1993.

6. Hamman RF, Halil T, Holland WW. Asthma in schoolchildren. Br J Prev Soc Med 1975; 29: 228-238.

7. Peckham C, Butler N. A national study of asthma in childhood. J Epidemiol Commun Health 1978; 32: 7985.

8. Kaplan BA, Mascie-Taylor CGN. Biosocial factors in the epidemiology of childhood asthma in a British national sample. J Epidemiol Commun Health 1985; 39: 153-156.

9. Kaplan BA, Mascie-Taylor CGN. Asthma and wheezy bronchitis in adolescents: biosocial correlates. J Asthma 1988; 25: 125-129.

10. Mitchell RG, Dawson B. Educational and social characteristics of children with asthma. Arch Dis Child 1973; 48: 467-471.

11. Lee DA, Winslow NR, Speight ANP, Hey EN. Prevalence and spectrum of asthma in childhood. BMJ 1983; 286: $1256-1258$.

12. Clifford RD, Radford M, Howell JB, Holgate ST. Prevalence of respiratory symptoms among 7 and 11 year old school children and association with asthma. Arch Dis Child 1989; 64: 1118-1125.

13. Chinn S, Rona RJ. Quantifying health aspects of passive smoking in British children aged 5-11 years. $J$ Epidemiol Commun Health 1991; 45: 188-194.

14. Strachan DP, Anderson HR, Limb ES, O'Neill A, Wells $\mathrm{N}$. A national survey of asthma prevalence, severity and treatment in Great Britain. Arch Dis Child 1994; 70: 174-178.

15. Charlton JRH, Hartley RM, Silver R, Holland WW. Geographical variation in mortality from conditions amenable to medical intervention in England and Wales. Lancet 1983; i: 691-696.

16. Higgins BG, Britton JR. Geographical and social class effects on asthma mortality in England and Wales. Respir Med 1995; 89: 341-346.

17. Townsend P, Phillimore P, Beattie A. Health and deprivation: inequalities and the North. London, Croon Helm, 1988.

18. Ben-Shlomo Y, White I, McKeigue PM. Prediction of general practice workload from census based social deprivation scores. J Epidemiol Commun Health 1992; 46: 532-536.

19. West Midlands Regional Health Authority. Agenda for Health. Report of the Regional Director of Public Health. Birmingham, West Midlands Regional Health Authority, 1994.

20. Wissow LS, Gittlesohn AM, Szklo M, Starfield B, Mussman M. Poverty, race, and hospitalization for childhood asthma. Am J Public Health 1988; 78: 777782.

21. Halfon N, Newacheck PW. Childhood asthma and poverty: differential impacts and utilization of health services. Pediatrics 1993; 91: 56-61. 
22. Majeed FA, Cook DG, Poloniecki J, Martin D. Using data from the 1991 census. BMJ 1995; 310: 15111514.

23. Simpson SN. Coverage of the Great Britain census of population and housing. J R Stat Soc 1994; 157: 313-316.

24. Ayres JG. Acute asthma in Asian patients: hospital admissions and duration of stay in a district with a high immigrant population. Br J Dis Chest 1986; 80: 242- 248.

25. Myers P, Ormerod LP. Increased asthma admission rates in Asian patients: Blackburn 1987. Respir Med 1992; 86(4): 297-300.

26. Ormerod LP. Adult Asian acute asthma admissions reassessed: Blackburn 1991-1992. Respir Med 1995; 89: 415-417.

27. Pararajasingham CD, Sittampalam L, Damani P, Pattemore PK, Holgate ST. Comparison of the prevalence of asthma among Asian and European children in Southampton. Thorax 1992; 47: 529-532.

28. Littlejohns P, Hollowell J, Hayward P, Prance S. Comparison of asthmatic patients admitted to hospital from health districts experiencing high and low asthma mortality rates. Postgrad Med J 1994; 70: 92-99.

29. Neville RG, Clark RC, Hoskins G, Smith B. National Asthma Attack Audit 1991-1992. BMJ 1993; 306: 559-562.

30. Strachan DP, Anderson HR. Trends in hospital admission rates for asthma in children. BMJ 1992; 304: 819-820.

31. O'Halloran SM, Heaf DP. Recurrent accident and emergency department attendance for acute asthma in children. Thorax 1989; 44: 620-626.

32. Storr J, Barrel E, Lenny W. Rising asthma admissions and self-referral. Arch Dis Child 1988; 63: 774-779.

33. Thakker Y, Sheldon TA, Long R, MacFaul R. Paediatric in-patient utilisation in a district general hospital. Arch Dis Child 1994; 70: 488-492.

34. Thompson JR, Lambert MA. Chronic persistent asthma presenting to an accident and emergency department: compliance with BTS. guidelines. Arch Emergency Med 1993; 10: 347-353.

35. Horn CR, Cochrane GM. Management of asthma in general practice. Respir Med 1989; 83: 67-70.

36. Gellert AR, Gellert SL, Iliffe SR. Prevalence and management of asthma in a London inner city general practice. Br J Gen Pract 1990; 40: 197-201.

37. Warner JO. Review of prescribed treatment for children with asthma in 1990. BMJ 1995; 311: 663-666.

38. Anderson HR, Bailey PA, Cooper JS, Palmer JC. Influence of morbidity, illness, label, and social, family, and health service factors on drug treatment of childhood asthma. Lancet 1981; ii: 1031-1032.

39. Mitchell EA, Stewart AW, Pattemore PK, Asher MI, Harrison AC, Rea HH. Socioeconomic status in childhood asthma. Int J Epidemiol 1989; 18: 888-890.
40. Connolly CK, Chan NS, Prescott RJ. The influence of social factors on the control of asthma. Postgrad Med J 1989; 65: 282-285.

41. Burney PGJ, Papacosta AO, Withey CH, Colley JRT, Holland WW. Hospital admission rates and the prevalence of asthma symptoms in 20 local authority districts. Thorax 1991; 46: 574-579.

42. McCormick A, Rosenbaum M. Royal College of General Practitioners, Office of Population Censuses and Surveys, Department of Health. Morbidity statistics from general practice, third national study: socioeconomic analyses. London, HMSO, 1990.

43. Littlejohns P, MacDonald LD. The relationship between severe asthma and social class. Respir Med 1993; 87: 139-143.

44. Burr ML, St Leger AS, Yarnell JWG. Wheezing, dampness and coal fires. Community Med 1981; 3: 205-209.

45. Burr ML, Miskelly FG, Butland BK. Merrett TG, Vaughan Williams E. Environmental factors and symptoms in infants at high risk of allergy. $J$ Epidemiol Commun Health 1989; 43: 125-132.

46. Burr ML, Mullins J, Merrett TG, Stott NCH. Indoor moulds and asthma. J R Soc Health 1988; 108: 99-101.

47. Strachan DP. Damp housing, mould allergy and childhood asthma. Proc R Coll Physicians Edinb 1991; 21: 140-146.

48. Townsend J, Roderick P, Cooper J. Cigarette smoking by socioeconomic group, sex and age: effects of price, income, and health publicity. BMJ 1994; 309: 923-927.

49. Murray AB, Morrison BJ. The effect of cigarette smoke from the mother on bronchial hyperresponsiveness and severity of symptoms in children with asthma. J Allergy Clin Immunol 1986; 77: 575-581.

50. Weitzman M, Gortmaker S, Walker DK, Sobol A. Maternal smoking and childhood asthma. Pediatrics 1990; 85: 505-511.

51. Couriel JM. Passive smoking and the health of children. Thorax 1994; 49: 731-734.

52. Walters SM, Miles J, Archer G, Ayres JG. Effects of an air pollution episode on respiratory function of patients with asthma. Thorax 1993; 48: 1063.

53. Walters S, Griffiths RK, Ayres JG. Temporal association between asthma in Birmingham and ambient levels of sulphur dioxide and smoke. Thorax 1994; 42: 133-140.

54. Edwards J, Walters S, Griffiths RK. Hospital admissions for asthma in preschool children: relationship to major roads in Birmingham, United Kingdom. Arch Environ Health 1994; 49: 223-227.

55. Walters SM, Phupinyokol M, Ayres JG. Hospital admission rates for asthma and respiratory disease in the West Midlands: their relationship to air pollution levels. Thorax 1995; 50: 948-954. 